\title{
Acoustic backscattering from salp and target strength estimation
}

\section{Pascal DAVID*, Odile GUERIN-ANCEY, Guillaume OUDOT, Jean-Paul VAN CUYCK}

Centre d'océanologie de Marseille (UMR 6540 CNRS/Dimar), université d'Aix-Marseille 2, campus de Luminy, case 901, 13288 Marseille cedex 9, France

\begin{abstract}
Although zooplanktonic organisms nearly have the acoustical impedance of water, they backscatter the sound. Strong acoustical echoes from salps were recorded in the Weddell sea at $150 \mathrm{kHz}$ (1992), in the Indian ocean at $12 \mathrm{kHz}$ (1994) and in the Mediterranean at 120 and $38 \mathrm{kHz}$ (1996). Sphere and cylinder models were applied to estimate the salp target strength. The salp is modelled by a cylindrical gelatinous body (length $L$ ) and a spherical nucleus (radius a). Backscattering from each part was estimated individually. With a detection threshold of $-100 \mathrm{~dB}$, the minimum body length and the minimum radius of nucleus to be theoretically detected were estimated for each of the following frequencies: $12,38,120$ and $150 \mathrm{kHz}$. A small salp $(L=14 \mathrm{~mm}$ and $a=1 \mathrm{~mm})$ would be only detected at 120 and $150 \mathrm{kHz}$ whereas a big salp $(L=100 \mathrm{~mm}$ and $a=7.5 \mathrm{~mm})$ would be also detected at 12 and $38 \mathrm{kHz}$. The nucleus of the salp can reveal by itself the salp's presence in the medium by concentrating a maximum weight into a minimum volume. The effects of variations in the input parameters on the estimated acoustical backscattering are discussed. (C) 2001 Ifremer/CNRS/IRD/Éditions scientifiques et médicales Elsevier SAS
\end{abstract}

Résumé - Étude de la détection acoustique des salpes et estimation de leur target strength. Bien que possédant une impédance acoustique voisine de celle de l'eau, les organismes zooplanctoniques réfléchissent tout de même les ondes acoustiques. De forts échos de salpes ont été enregistrés en mer de Weddell (1992) à l'aide d'un sondeur à $150 \mathrm{kHz}$, dans l'océan Indien (1994) à $12 \mathrm{kHz}$ et en Méditerranée (1996) à 120 et $38 \mathrm{kHz}$. Pour comprendre pourquoi ces organismes présentent de si forts échos, deux modèles (le cylindre fluide et la sphère fluide) ont été utilisés pour estimer le target strength des salpes. L'anatomie de ce zooplancton est modélisée par un corps cylindrique gélatineux (de longueur $L$ ) et un noyau dur sphérique (de rayon $a$ ). La rétrodiffusion de l'onde par chacune de ces parties est étudiée séparément. Deux tailles ont été considérées dans cette étude : une petite salpe $(L=14 \mathrm{~mm}, a=1 \mathrm{~mm})$ et une grosse salpe $(L=100 \mathrm{~mm}$, $a=7.5 \mathrm{~mm}$ ). Le seuil de détection étant placé à $-100 \mathrm{~dB}$, les tailles théoriques minimum de détection pour le corps et pour le noyau ont été estimées pour 12, 38, 120 et $150 \mathrm{kHz}$. D'après les modèles, le corps gélatineux et le noyau des petites salpes ne sont détectables qu'à 120 et $150 \mathrm{kHz}$ alors que ceux des grosses salpes sont également détectables à 12 et $38 \mathrm{kHz}$. Le noyau peut aussi révéler seul la présence de la salpe dans le milieu en concentrant un maximum de masse dans un volume minimum. L'effet des variations du paramètre d'entrée des modèles fait l'objet de discussion. (C) 2001 Ifremer/CNRS/IRD/Éditions scientifiques et médicales Elsevier SAS

salp / target strength / underwater acoustics

salpe / target strength / acoustique sous-marine

*Correspondence and reprints: fax: +33 491829194.

E-mail address: david@com.univ-mrs.fr (P. DAVID).

(C) 2001 Ifremer/CNRS/IRD/Éditions scientifiques et médicales Elsevier SAS. Tous droits réservés 


\section{INTRODUCTION}

Acoustic systems allow one to localise, quantify, identify and study the zooplankton repartition in space in realtime. Although it is easy to make acoustical observations on marine particles, it is difficult to calibrate the acoustic systems with direct measurements. Nets are used to sample the sea. Generally, a mixture of zooplankton (siphonophores, copepods, pteropods, euphausiids and others) is collected together. Moreover, it is difficult to estimate accurately the density of the plankton populations from a net sample because of uncertainties on the efficiency of the net. It is also difficult to know what is the individual contribution of each species in the echo or in the resulting reverberation. When the plankton population is monospecific (David et al. 1999) which is a very rare case in the natural medium, or when some individual sizes are much bigger than the others, it is easier to estimate their acoustical part in the production of an echo. But the first important question is to know whether such individual targets are able to produce or not an echo or a reverberation. For this reason, it is important to know what particles are on the limit of detectability. The effective scattering from a body depends on its dimensions, relative density and elasticity compared to those of surrounding seawater, and its orientation with respect to the beam angle of the sonar.

However, zooplankton backscatters sound Beamish 1971: Richter, 1985a). The scattering of zooplanktonic organisms has been studied at different frequencies Greenblatt, 1981: Wiehe et al, 1990). The acoustical scattering allows one to study plankton distribution Richter, 1985b and relationship with marine physical parameters (Murav'yev, 1984). Species identification and plankton size estimation (Kristensen 1986) require multifrequency sounders Greenlaw and Johnson, 1983. Pieper et al 1990; Greene et al, 1989; Guerin-Ancey and David.1993) and mathematical processes (Martined and David, 1992) Very small plankton can be studied by using a high frequency echosounder when the number of individuals is big enough and when the body of the zooplankton presents a sufficient impedance contrast with the surrounding medium Kogeler et al__ 1987). Sound scattering models by cylinders of finite length Stanton 1988. 1989a), spherical and elongated bodies (Stanton 1989b) spherical and elongated shelled bodies Stanton. 1990) and average echoes from randomly oriented random-length finite cylinders Stanton et al__ 1993 were developed to estimate target strength of marine organisms.

The gelatinous plankton seems to stand on the acoustical detection limit of the zooplankton. Its density contrast is low because of the large percentage of water (about $96 \%$ ) inside their body. Pelagic gelatinous zooplankton includes different groups such as coelenterae (medusa) and tunicates (salps). Medusa have been studied by Andreeva and Tarasov (1985). The target strength of some non-contractile animals such as Cnideria and Ctenophora was measured by Wiebe et al. (1990). Although salps are important members of zooplankton communities in the world Wiehe_et_al, 1979) their acoustical properties have yet been little studied (Stanton et al., 1990).

Salps have a transparent body with a cylindrical shape and a spherical dense visceral mass called nucleus. Salps are active swimmers and filters: they swim at 3-5 $\mathrm{m} \cdot \mathrm{min}^{-1}$ with synchronous contractions of their circular muscles, filtering $45 \mathrm{~cm}^{3} \cdot \mathrm{min}^{-1}$, and feeding $90 \%$ of the time (Madin, 1984; Bone et al, 1991). Salps are able to overcome predation and supplant the other filter feeding species. The diel vertical migration of important Salpa aspera biomass was observed in the slope water of the North Atlantic ocean Wiebe et al. 1979.

Quoted by Macaulay et al_(1984) in the Scotia sea, salps have been more easily detected with a $200-\mathrm{kHz}$ acoustic system than at $120 \mathrm{kHz}$. On the other hand, a series of experiments in tank, on the scattering of sound from 26-mm long Salpa aspera under $200 \mathrm{kHz}$, led Stanton et al_(1994) to conclude that salp is an inefficient scatterer of sound.

We participated in oceanographic cruises, in different areas of the world, where salps were detected by acoustics and fished: Salpa thompsoni at $150 \mathrm{kHz}$ in the north-east of the Weddell sea (1992) and at $12 \mathrm{kHz}$ in the Indian Austral ocean (1994); Salpa fusiformis and Salpa maxima, at 120 and $38 \mathrm{kHz}$, in the Mediterranean (1996); these salps measured from 2 to $20 \mathrm{~cm}$ long.

The purpose of this paper is to answer the question: Why are salps good acoustical reflectors although they are gelatinous organisms? 


\section{MATERIALS AND METHODS}

\subsection{Detection}

During the JGOFS cruise 'Spring at the ice edge' (September 29 to November 29, 1992) in the NE of the Weddell sea aboard the RV Polarstern, plankton detection was realised during the entire cruise. Using a Honeywell Elac $150 \mathrm{kHz}$ echosounder, we studied the 0 to $200 \mathrm{~m}$ layer, from the sea-ice area in the south $\left(59^{\circ} 30 \mathrm{~S}, 06^{\circ} 00 \mathrm{~W}\right)$ to the free waters in the north $\left(46^{\circ} 59 \mathrm{~S}, 06^{\circ} 00 \mathrm{~W}\right)$. At the same time, plankton samples were collected with a RMT net. Twice, plankton fishing revealed a very high concentration of Salpa thompsoni. Many small salps from 2 to $3 \mathrm{~cm}$ long were collected (5502'00" S; 05 59'44” W, S\%: 33.74 PSU, T: $-1.1^{\circ} \mathrm{C}$, $\rho:$ 1.03048) and some big salps measuring about $10-12 \mathrm{~cm}$ long were caught $\left(47^{\circ} 01^{\prime} 06^{\prime \prime} \mathrm{S} ; 06^{\circ} 00^{\prime} 73^{\prime \prime} \mathrm{W}\right.$, S\%: 33.75 PSU, T: $\left.4.2{ }^{\circ} \mathrm{C}, \rho: 1.03001\right)$.

During the JGOFS Antares 2 cruise (January 26 to March $23,1994)$ in the Indian area of the Austral ocean aboard the RV Marion Dufresne, acoustical survey at $12 \mathrm{kHz}$ detected salps at $250 \mathrm{~m}$ depth $\left(48^{\circ} 57^{\prime} \mathrm{S} ; 62^{\circ} \mathrm{E}, \mathrm{S} \%\right.$ : 34.0196, T: $\left.2.0948{ }^{\circ} \mathrm{C}, \rho: 1.0271799\right)$. Salpa thompsoni had been fished by WPZ and Omori nets. An example of an echogram is shown in gigure

Salps had also been detected during the European programme PEP (MAST3-CT95-0013) 'Impact of a climatic gradient on the physiological ecology of a pelagic crustacean' (April 1996 to August 1998) aboard the RV Heinke in the Mediterranean sea, Ligurian area. Strong

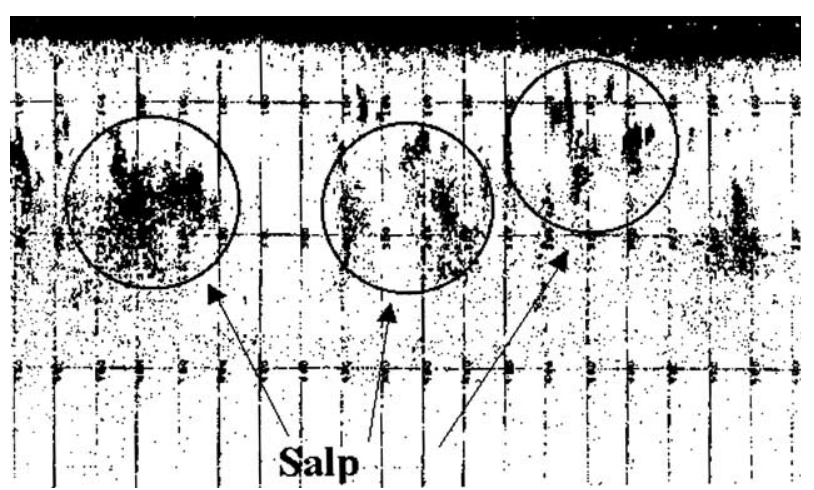

Figure 1. Echogram of strong salp echoes at $12 \mathrm{kHz}$ in the Austral ocean. echoes from salps had been recorded with a 38- and $120-\mathrm{kHz}$ Biosonics echosounder. The target identification was made by net sampling with a 9-nets system Mocness. Many Salpa fusiformis (around $2 \mathrm{~cm}$ long) and some Salpa maxima (around $20 \mathrm{~cm}$ long) were caught in all the water column $\left(43^{\circ} 54^{\prime} \mathrm{N}\right.$; 0750' E, S\%: $38.3 \mathrm{PSU}$, T: $\left.20{ }^{\circ} \mathrm{C}, \rho: 1.02880\right)$.

\subsection{The models}

To explain the strong salp echoes, we used two mathematical models estimating the target strength (TS) of these animals: the cylinder model for the body, and the sphere model for the supposed spherical nucleus.

The conceptual models take as a basis a simplified shape of the target and its acoustical characteristics. They give the predicted backscattering cross-section and allow to determine the target strength. The backscattered energy depends mainly on excitation frequency, size and shape of the target, and acoustical impedance contrast between the target and the medium, i.e. the ratio of the density and the sound speed between the medium and the inside of the target.

\subsubsection{Finite fluid cylinder model}

Salps are elongated gelatinous marine organisms whose body axis is generally horizontal or slightly inclined by the weight of the nucleus. To determine the backscattering from the gelatinous body, we used the finite fluid cylinder model of Stanton (1988). This model determines the acoustical pressure $P_{\text {scat }}$ backscattered by a finite fluid cylinder (length $L$ and radius $a$ ). When an incident plane wave of amplitude $P_{\mathrm{o}}$ is normal at a cylinder:

$$
P_{\text {scat }}=P_{\mathrm{o}}\left(\mathrm{e}^{i k r} / r\right) \frac{-i L}{\pi} \frac{\sin (\Delta)}{\Delta} \sum_{m=0}^{\infty} B_{m}(-i)^{m} \cos (m \phi)
$$

where $k$ is the wave-number, $r$ the distance between the receiver and the cylinder, $\Delta=1 / 2(k L \cos \theta), \theta$ the angle between the source direction and the cylinder axis, $\phi$ the angle between the source direction and the receiver direction and $B_{m}$ depends on $a, g$ (density contrast between inside the cylinder and the medium), $h$ (sound speed contrast between inside the cylinder and the medium), $k, k^{*}$ (the wave-number inside the cylinder), $\varepsilon_{m}$ (the Neumann numbers: $\varepsilon_{0}=1$ and $\varepsilon_{m}=2$ for $m=1,2,3, \ldots)$ and on Bessel functions. 
The differential scattering cross section is

$$
\sigma(\theta, \phi)=\left|\frac{P_{\text {scat }}}{P_{\mathrm{o}}\left(\mathrm{e}^{i k r} / r\right)}\right|^{2}
$$

Finally, the target strength of the cylindrical body is

$$
\mathrm{TS}=10 \log \sigma_{\mathrm{bs}}=10 \log \sigma(\theta=\pi / 2, \phi=\pi)
$$

\subsubsection{Fluid sphere model}

This model, developed by Anderson_(1950) is used to estimate the backscattering cross-section $\sigma_{\mathrm{bs}}$ and the TS of a salp's nucleus which is supposed to be spherical.

The normalised backscattering cross section of the sphere (radius $a$ ) is:

$$
\frac{\sigma}{\pi a^{2}}=\left(\frac{2}{k a}\right)^{2}\left|\sum_{m=0}^{\infty} \frac{(-1)^{m}(2 m+1)}{1+i C_{m}}\right|^{2}
$$

$C_{m}$ depends on the spherical Bessel and Neumann functions, the wave-number in the medium $k$, the wavenumber inside the sphere $k^{\prime}$, the density contrast $g$, the sound speed contrast $h$, and the radius $a$.

The TS verifies: TS $=10 \log \left(\sigma_{\mathrm{bs}}\right)=10 \log (\sigma / 4 \pi)$.

\subsection{Numerical application conditions}

The salp is modelled in two parts (figure 2): a cylindrical gelatinous body (length $L$, radius $A$ ) and a spherical nucleus (radius $a$ ). The backscattering from each part was studied separately.

For these calculations, $g$ and $h$ parameter values are estimated: $g$ is the ratio of the density of the body

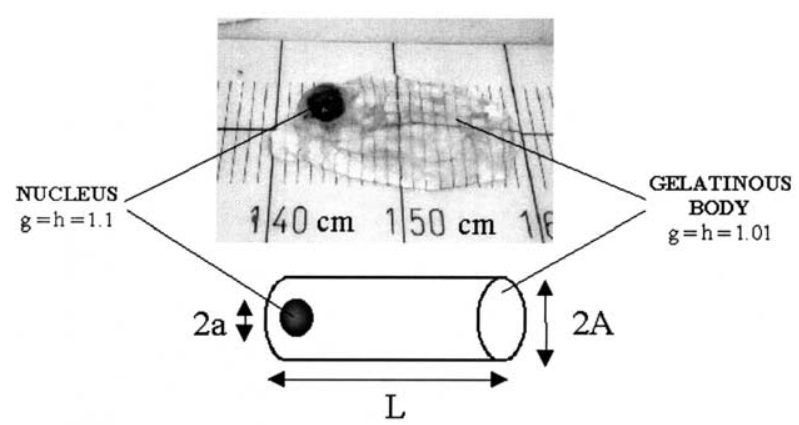

Figure 2. Photo of a 20-cm long Salpa maxima and the geometrical model. material with respect to the density of the surrounding medium, $h$ the ratio between the sound speed of the body material and the surrounding medium.

The density of the salp body or nucleus is difficult to measure because the salps adapt their morphology, physiology and behaviour to the medium. The density of salps is also difficult to calculate because the weight and the volume of their body are variable. The weight depends on the elemental and biochemical composition of the salp. Parsons et al. (1984) found that salps are composed of $96 \%$ water. Studies carried out by Curl 1962) and Madin et_al_(1981) showed that the salp dry weight is $73 \%$ ash (of which $71-77 \%$ salts) and $27 \%$ ash-free dry weight (of which $29.4 \%$ carbon, $6.3 \%$ nitrogen, $45 \% \mathrm{H}_{2} \mathrm{O}$ ). The salt percentage is very high in salps compared to copepods (2-6\%) and to Euphausiids (8-9 \%) (Parsons et al. 1984). The gelatinous animals contain a large percentage of water but also a large amount of salt and a high ash weight.

Salps are continuous and active swimmers, and a considerable portion of their body wall is composed of muscle Madin et al. 1981)

It is difficult to make an accurate weighing with preserved organisms. The weight loss due to preservation is supposed to be $24 \%$ of live weight SSmith et al_ 1985. The measurements with preserved organisms vary widely. The preserved length is about $75 \%$ of live length, the preserved volume is approximately $45 \%$ of live volume.

There is no data for $g$ and $h$ for salps quoted in the literature. But, for a weakly scattering fluid body, the sound speed contrast is small and varies generally from 1.01 to 1.05 for zooplankton Kogeler et al. 1987; Kristensen. 1986). Stanton et al_(1994) used another model and characterised the salp with a parameter $R=(g h-1) /(g h+1)=4.110^{-3}$. This value corresponds to the case $g=h \approx 1.004$ which are especially low values.

Between swimming episodes and also when it dies, a salp sinks into the sea. So, we can estimate that the density of the salp is higher than the surrounding seawater density. As the average sea density is close to 1.03 , the salp density is supposed to be at least equal to 1.04 , knowing that its components are $71-77 \%$ salts which are heavier than the organic matter. Then, the density contrast of the gelatinous body has been esti 
mated to be $g=1.01$ in order to be in an unfavourable case. The nucleus concentrating the main part of the dry weight in a smaller volume, its density should be higher than the body density. In this study, the density contrast for the nucleus has been chosen as $g=1.1$, this value agrees with the one used by Holliday and Pieper Holliday and Pieper. 1980 who applied a fluid sphere model for zooplankton backscattering. Values of $h$ have been chosen at 1.01 for the gelatinous body and 1.1 for the nucleus.

Two different salp sizes will be used:

- Small salp: $L=14 \mathrm{~mm} ; A=1.75 \mathrm{~mm} ; a=1 \mathrm{~mm}$;

- Big salp: $L=100 \mathrm{~mm} ; A=12.5 \mathrm{~mm} ; a=7.5 \mathrm{~mm}$.

An intermediate value of $1515 \mathrm{~m} \cdot \mathrm{s}^{-1}$ for the sound speed in the medium has been used for the calculation.

For the estimation of the backscattering cross-section of the finite cylinder of Stanton and the sphere model of Anderson, the computations have been done with only the first two terms of the infinite sum. This choice agrees with the fact that the highest correlation between theory and data occurred when only the first two terms were kept Pieper and Holliday. 1984: Stanton. 1988.

\section{RESULTS AND DISCUSSION}

The variation of the TS with the frequency (in logarithm scale) is shown in figure 3 for the cylinder model and in Goure 4 for the sphere model with frequencies from 5 to $500 \mathrm{kHz}$. In the two figures, for the lowest frequencies, the global tendency is linear (Rayleigh region) but starting from a critical value of frequency, there are oscillations which correspond with interferences between the reflected waves from the surface of the target and the internal waves inside the target. This resonance phenomena makes uncertain the detection of salps at particular frequencies. But there are two main differences between the two models: the critical frequency in the cylinder model induces a much higher decrease of TS than in the sphere model; the oscillations in the cylinder model keep a positive average slope, whereas in the sphere model, the average of the oscillations remains constant.

Eigure 5 shows the variation of TS with the cylinder length at $12,38,120$ and $150 \mathrm{kHz}$. The radius of the cylinder is assumed to be proportional to the length $(A=L / 8)$. A quick increase of TS is observed for the
FLUID CYLINDER MODEL

( $\mathrm{a}=5 \mathrm{~mm}, \mathrm{~L}=\mathbf{4 0} \mathrm{mm}, \mathrm{g}=\mathrm{h}=1.01$ )

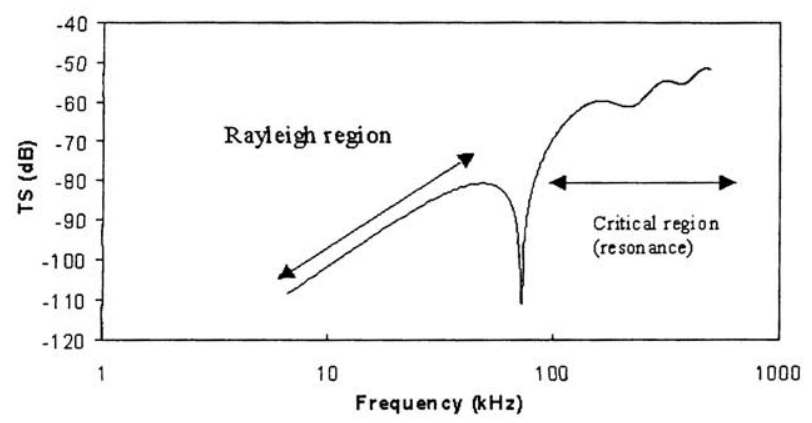

Figure 3. Target strength of a $40-\mathrm{mm}$ salp cylindrical body versus frequency.

smallest values of length at any frequency (according to the Rayleigh region). Then, we observe that all the curves, except the $12-\mathrm{kHz}$ one, have their own particular range of $L$ in which the TS decreases suddenly. The $L$ value which corresponds to the smallest TS in this particular range, is about $19 \mathrm{~mm}$ for $150 \mathrm{kHz}, 24 \mathrm{~mm}$ for $120 \mathrm{kHz}$ and $76 \mathrm{~mm}$ for $38 \mathrm{kHz}$. This means for example that at $150 \mathrm{kHz}$, a $15-\mathrm{mm}$ long salp has a TS $50 \mathrm{~dB}$ higher than a $19-\mathrm{mm}$ one.

We notice that the product between the frequency $F$ and the critical value of $L$ remains constant. It means that the cylinder model has only one critical value for the product $F \times L$ and each frequency has its own particular critical value of $L$. The critical value of $F \times L$ allows to calculate the critical value of $L$ at $12 \mathrm{kHz}$ and we obtain $241 \mathrm{~mm}$ which is outside the considered range of $L$ in figure 5 (tabled).

\section{FLUID SPHERE MODEL ( $a=5 \mathrm{~mm}, g=h=1.1$ )}

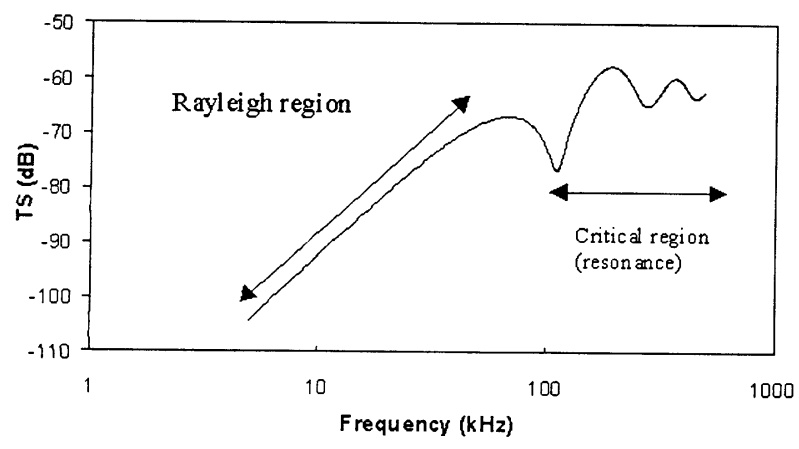

Figure 4. Target strength of a 5-mm radius nucleus versus frequency. 
CYLINDER MODEL : TS vS BODY LENGTH

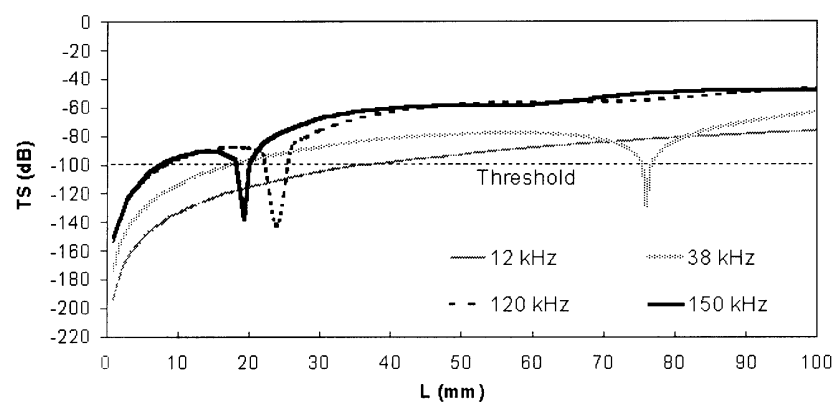

Figure 5. Target strength of a salp body versus body length at 12,38 , 120 and $150 \mathrm{kHz}$.

The TS estimated by the cylinder model for the 14-mm small salp body is: $-125.4 \mathrm{~dB}$ at $12 \mathrm{kHz},-105.8 \mathrm{~dB}$ at $38 \mathrm{kHz},-90.3 \mathrm{~dB}$ at $120 \mathrm{kHz}$, and $-90 \mathrm{~dB}$ at $150 \mathrm{kHz}$. Considering a detection threshold of $-100 \mathrm{~dB}$, we conclude that the small salp body is only detected at 120 and $150 \mathrm{kHz}$. For the big salp body $(100 \mathrm{~mm})$, the TS is $-76.4 \mathrm{~dB}$ at $12 \mathrm{kHz},-63.2 \mathrm{~dB}$ at $38 \mathrm{kHz},-47 \mathrm{~dB}$ at $120 \mathrm{kHz}$ and $-47.4 \mathrm{~dB}$ at $150 \mathrm{kHz}$. Here we found very high values of TS, especially at high frequencies: at 120 and $150 \mathrm{kHz}$, the TS of the $100-\mathrm{mm}$ long salp body is similar to the TS of a 40-mm swimbladder fish. We can conclude that the big salp could be easily detected at all these frequencies. The difference between the TS of the big cylindrical body and the TS for the small one at both 120 and $150 \mathrm{kHz}$ means that 20000 small salp bodies provide about the same intensity as only one big salp body.

Eigure shows the TS of the nucleus versus the radius $a$ at $12,38,120$ and $150 \mathrm{kHz}$. As in figure 5, we could

Table I. Critical values of salp size due to resonance phenomena.

\begin{tabular}{ccccccc}
\hline & \multicolumn{3}{l}{ Sphere model } & \multicolumn{4}{l}{ Cylinder model } \\
\cline { 2 - 7 } $\begin{array}{l}\text { Freq. } \\
\text { (kHz) }\end{array}$ & $a(\mathrm{~mm})$ & $\begin{array}{l}L \text { equiv. } \\
(\mathrm{mm})\end{array}$ & $F \times a$ & $L(\mathrm{~mm})$ & $\begin{array}{l}a \text { equiv. } \\
(\mathrm{mm})\end{array}$ & $F \times L$ \\
\hline 12 & $45^{*}$ & $630^{*}$ & 540 & $240^{*}$ & $17.1^{*}$ & 2880 \\
38 & 14 & 196 & 532 & 76 & 5.4 & 2888 \\
120 & 4.7 & 65.8 & 564 & 24 & 1.7 & 2880 \\
150 & 3.6 & 50.4 & 540 & 19 & 1.35 & 2850 \\
\hline
\end{tabular}

* These theoretical values have been calculated but not observed in the considered range of size. A $24-\mathrm{cm}$ long body is a realistic size for a salp but not $63 \mathrm{~cm}$.
SPHERE MODEL : TS vS NUCLEUS RADIUS

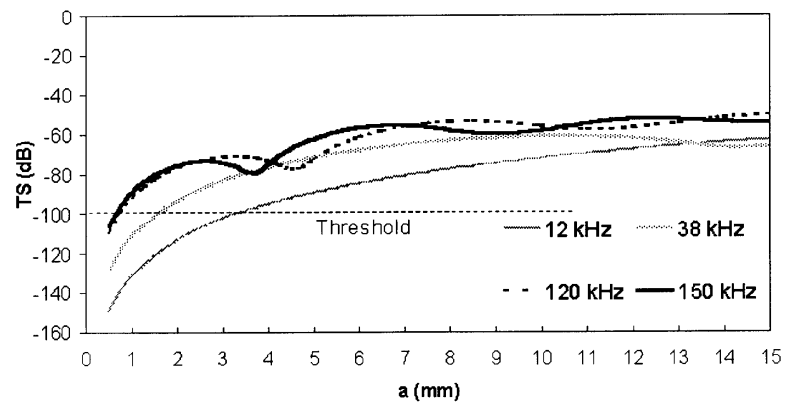

Figure 6. Target strength of the spherical nucleus versus its radius at $12,38,120$ and $150 \mathrm{kHz}$

observe a quick increase of TS for smallest values of $a$ at any frequency followed by the resonance oscillations. The critical values of radius correspond with an average decrease of TS of $6.5 \mathrm{~dB}$. But the higher the frequency is, the quicker this local decrease. The critical values of $a$ are $3.6 \mathrm{~mm}$ at $150 \mathrm{kHz}, 4.7 \mathrm{~mm}$ at $120 \mathrm{kHz}$ and $14 \mathrm{~mm}$ at $38 \mathrm{kHz}$. With the proportionality ratio $(L / a=14)$, we can calculate the corresponding body length and we find the critical body length of $50.4 \mathrm{~mm}$ at $150 \mathrm{kHz}, 65.8 \mathrm{~mm}$ at $120 \mathrm{kHz}$ and $196 \mathrm{~mm}$ at $38 \mathrm{kHz}$. Table allows to compare these results to those for the cylindrical body: the spherical nucleus and the cylindrical body of the same salp can not be in the critical situation at the same frequency.

Here again, the product between the frequency and the critical value of the size is somehow constant (table $)$. It means that the product $F \times a$ is an important parameter of the sphere model. The result for this product allows to estimate the critical nucleus size at $12 \mathrm{kHz}$ to be $45 \mathrm{~mm}$. This parameter is directly linked to an acoustical classical parameter $k \times a$, where $k$, the wave-number, is the inverse of the wavelength, so that $k \times a$ corresponds to the ratio between the target size $a$ and the spatial period of the incident wave. All the backscattering models give the TS versus $k \times a$ to provide the TS at any frequency and for any size of target.

The TS for the small nucleus is estimated to be $-130.7 \mathrm{~dB}$ at $12 \mathrm{kHz},-110.9 \mathrm{~dB}$ at $38 \mathrm{kHz},-91.9 \mathrm{~dB}$ at $120 \mathrm{kHz}$ and $-88.5 \mathrm{~dB}$ at $150 \mathrm{kHz}$. Considering a threshold of $-100 \mathrm{~dB}$, it means that the 120 and $150 \mathrm{kHz}$ sounder could detect the small salp only by its nucleus. For the big nucleus, the TS is estimated to be $-78.8 \mathrm{~dB}$ at $12 \mathrm{kHz},-63.8 \mathrm{~dB}$ at $38 \mathrm{kHz},-54.5 \mathrm{~dB}$ at $120 \mathrm{kHz}$ 
Table II. Target strength (TS) estimation for small and big salps.

\begin{tabular}{rllll}
\hline & \multicolumn{2}{l}{ Sphere model } & \multicolumn{2}{l}{ Cylinder model } \\
\cline { 2 - 5 } & Small salp & Big salp & Small salp & Big salp \\
\hline $12 \mathrm{kHz}$ & -130.7 & -78.8 & -125.4 & -76.4 \\
$38 \mathrm{kHz}$ & -110.9 & -63.8 & -105.8 & -63.2 \\
$120 \mathrm{kHz}$ & -91.9 & -54.4 & -90.3 & -46.9 \\
$150 \mathrm{kHz}$ & -88.5 & -56.3 & -90.0 & -47.4 \\
\hline
\end{tabular}

and $-56.2 \mathrm{~dB}$ at $150 \mathrm{kHz}$. The nucleus of the big salp could then be detected at any of these four frequencies. The difference between the TS of the big nucleus and the TS for the small one at both 120 and $150 \mathrm{kHz}$ means that more than 3000 small nucleus are needed to provide the same intensity as only one big nucleus.

Table 1 recapitulates the estimated TS for small and big salps by the two models. We observe for all the data taken from the Rayleigh region (small salp at any frequency or big salp at 12 and $38 \mathrm{kHz}$ ) that the models give estimations which are close to each other and that the nucleus backscatters only a little less energy than the corresponding body. In the case of the big salp at 120 and $150 \mathrm{kHz}$, the cylinder model gives a TS $8 \mathrm{~dB}$ higher than the sphere model (about $-55 \mathrm{~dB}$ for the sphere model against $-47 \mathrm{~dB}$ for the cylinder one). A previous remark on the difference between the oscillations of the two models could explain why the cylinder model, which keeps a positive average slope for high frequencies, provides a much higher TS than the sphere model in which the oscillation average remains constant.

Table $I$ provides the estimated minimum size of the target to be detected at any frequency with a detection threshold of $-100 \mathrm{~dB}$ (dashed line in Gigures 5 and 6 ). We find that the cylinder body is always more reflecting than the nucleus, for example the body of a 7.5-mm long salp will be detected at $150 \mathrm{kHz}$ but not its nucleus. Then the minimum size of detected salps due to their cylindrical body is: $7.5 \mathrm{~mm}$ at $150 \mathrm{kHz}, 8.5 \mathrm{~mm}$ at $120 \mathrm{kHz}$, $17.5 \mathrm{~mm}$ at $38 \mathrm{kHz}$ and $37.5 \mathrm{~mm}$ at $12 \mathrm{kHz}$. But the cylinder model has more resonance troubles than the sphere one; at $150 \mathrm{kHz}$, we could not detect salp body between 18 and $20 \mathrm{~mm}$ long, at $120 \mathrm{kHz}$, the difficulty appears between 22.5 and $26 \mathrm{~mm}$ and at $38 \mathrm{kHz}$ between 75 and $77 \mathrm{~mm}$. Under these critical conditions, salp
Table III. Minimum detected size for the body and the nucleus of salps.

\begin{tabular}{rllll}
\hline & \multicolumn{2}{l}{ Sphere model } & \multicolumn{2}{l}{ Cylinder model } \\
\cline { 2 - 5 } & $a(\mathrm{~mm})$ & $L$ equiv. $(\mathrm{mm})$ & $L(\mathrm{~mm})$ & $a$ equiv. $(\mathrm{mm})$ \\
\hline $12 \mathrm{kHz}$ & 3.2 & 44.8 & 37.5 & 2.67 \\
$38 \mathrm{kHz}$ & 1.5 & 21.0 & 17.5 & 1.25 \\
$120 \mathrm{kHz}$ & 0.75 & 10.5 & 8.5 & 0.60 \\
$150 \mathrm{kHz}$ & 0.6 & 8.4 & 7.5 & 0.53 \\
\hline
\end{tabular}

bodies are not detected but the salp could be detected because of its nucleus which backscatters enough energy. For example, a 19-mm long salp corresponds to a TS at $150 \mathrm{kHz}$ of $-81.9 \mathrm{~dB}$ because of its nucleus of $1.35 \mathrm{~mm}$ radius, whereas its body has a TS of $-138 \mathrm{~dB}$. The conclusion is that the nucleus backscattering is important enough to compensate the resonance troubles of the cylindrical body. So each organism could be detected only by one of its organs if this organ has some strong acoustical parameter like fish with their swimbladder.

The influence of the input parameter values has yet to be discussed. The density of a nucleus can be much larger than the minimum density of all the body in buoyancy. Figure 7 shows the impact of different values of $g$ on the TS of a $2-\mathrm{mm}$ nucleus with the fluid sphere model assuming that $g$ and $h$ are independent ( $h=1.1$ and $g$ varied from 1 to 1.2). The result is that from $g=1.01$ to 1.1 , the TS increased by 5 and by $3 \mathrm{~dB}$ between $g=1.1$

\section{TS vs $\mathrm{g}$ for a $2 \mathrm{~mm}$ nucleus radius}

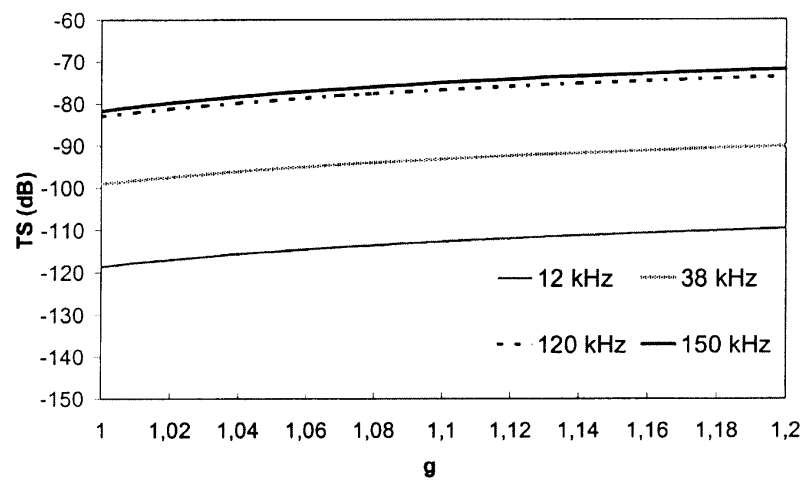

Figure 7. Influence of the density contrast $g$ on the target strength of a 2 -mm nucleus radius. 
and 1.2. All the curves are sensibly parallel, it means that variations of $g$ would have the same influence at each frequency.

\section{CONCLUSION}

This study shows the importance of the mathematical models used to estimate the target strength (TS) of an individual target such as a planktonic organism, when its size is tiny and when it is weakly backscattering. The TS can be calculated using a mathematical model, supposing a simple shape target of a cylinder or a sphere. The target could correspond to just one organ of the living animal.

The conclusion of this study is that salp could be detected at body lengths of $7.5 \mathrm{~mm}$ at $150 \mathrm{kHz}, 8.5 \mathrm{~mm}$ at $120 \mathrm{kHz}, 17.5 \mathrm{~mm}$ at $38 \mathrm{kHz}$ and $37.5 \mathrm{~mm}$ at $12 \mathrm{kHz}$. But the resonance phenomena could create troubles in certain conditions, especially for the backscattering from the cylindrical body. The nucleus could then provide enough energy to allow the salp detection even if the body is not detected. This conclusion concerns each individual separately and it is well known that salps can link to each other to make a blastozooid form which can reach several meters in length. This form constitutes then a much larger acoustical target and provides a characteristic vertical echo on the echogram.

The physiological behaviour of salps leads to uncertainties in the density of the body or the nucleus and in its acoustical evaluation. It would be interesting to study more salp biometrics in order to improve biomass estimations made with acoustical data.

\section{Acknowledgements}

The authors express their thanks to those who supported all the studies: AWI for the cruise in the Weddell sea (1992), IFRTP for the Indian ocean cruise (1994) and CNRS and European Union for the PEP programme in the Mediterranean sea (1996).

\section{REFERENCES}

Anderson, V.C., 1950. Sound scattering from a fluid sphere. J. Acoust. Soc. Am. 22, 426-431.

Andreeva, I.B., Tarasov, L.L., 1985. The acoustical scattering by medusae, Oceanology XXV. Academy Hayk CCCP, Moscow.
Beamish, P., 1971. Quantitative measurements of acoustic scattering from zooplankton organisms. Deep-Sea Res. 18, 811-822.

Bone, Q., Braconnot, J.C., Ryan, K.P., 1991. On the pharyngeal feeding filter of the Salp Pegea confoederata (Tunicata: Thaliacea). Acta Zool. (Stockholm) 72, 55-60.

Curl, H., 1962. Standing crops of carbon, nitrogen, and phosphorus, and transfer between trophic levels, in continental shelf waters south of New York. Rapp. P.-V. Cons. Int. Expl. Mer 153, 183-189.

David, P.M., Guerin-Ancey, O., Van Cuyck, J.P., 1999. Acoustic discrimination of two zooplankton species (mysid) at 38 and 120 kHz. Deep-Sea Res. I 46, 319-333.

Greenblatt, P., 1981. Sources of acoustic backscattering at $87.5 \mathrm{kHz}$. J. Acoust. Soc. Am. 70, 134-142.

Greene, C.H., Wiebe, P.H., Burczynski, J., 1989. Analysing zooplankton size distributions using high-frequency sound. Limnol. Oceanogr. 34, 129-139.

Greenlaw, C.F., Johnson, R.K., 1983. Multiple-frequency acoustical estimation. Biol. Oceanogr. 2, 227-252.

Guerin-Ancey, O., David, P.M., 1993. Use of a multibeammultifrequency sounder to study the distribution of small zooplankton. Deep-Sea Res. 40, 119-128.

Holliday, D.V., Pieper, R.E., 1980. Volume scattering strengths and zooplankton distributions at acoustic frequencies between 0.5 and 3 MHz. J. Acoust. Soc. Am. 67, 135-146.

Kogeler, J.W., Falk-Petersen, S., Kristensen, A., Pettersen, F., Dalen, J., 1987. Density and sound speed contrasts in sub-Antarctic zooplankton. Polar Biol. 7, 231-235.

Kristensen, K., 1986. Acoustic estimation of size distribution and abundance of zooplankton. J. Acoust. Soc. Am. 80, 601-611.

Macaulay, M.C., Daly, K.L., Mathisen, O.A., 1984. Acoustic assessment of the distribution and abundance of micronekton and nekton in the Scotia Sea. Antarct. J. USA 19, 141-143.

Madin, L.P., 1984. Field observations on the feeding behaviour of salps (Tunicata, Thaliacea). Mar. Biol. 25, 143-147.

Madin, L.P., Cetta, C.M., McAlister, V.L., 1981. Elemental and biochemical composition of salps (Tunicata: Thaliacea). Mar. Biol. 63, 217-226.

Martinez, C., David, P.M., 1992. Principal component calibration models in the acoustic evaluation of zooplankton size spectra. J. Acoust. Soc. Am. 92, 1428-1439.

Murav'yev, S.S., 1984. On the relationship between the structure of the deep scattering layers in the ocean and hydrophysical processes. Oceanology 24, 195-199.

Parsons, T.R., Takahashi, M., Hargrave, B., 1984. Biological Oceanography Processes. Pergamon Press, Oxford.

Pieper, R.E., Holliday, D.V., 1984. Acoustic measurements of zooplankton distributions in the sea. J. Const. Int. Explor. Mer 41, 226-238.

Pieper, R.E., Holliday, D.V., Kleppel, G.S., 1990. Quantitative zooplankton distributions from multifrequency acoustics. J. Plankton Res. 12, 433-441.

Richter, K.E., 1985a. Acoustic scattering at 1.2 MHz from individual zooplankters and copepod populations. Deep-Sea Res. 32, 149-161. 
Richter, K.E., 1985b. Acoustic determination of small-scale distributions of individual zooplankters and zooplankton aggregations. Deep-Sea Res. 32, 163-182.

Smith, S.L., Lane, P.V.Z., Schwarting, E.M., 1985. Zooplankton Data Report: Shelf Edge Exchange Processes (SEEP) I, Technical report number BNL 36260. Brookhaven Laboratory, Upton, New York.

Stanton, T.K., 1988. Sound scattering by cylinders of finite length. I. Fluid cylinders. J. Acoust. Soc. Am. 83, 55-63.

Stanton, T.K., 1989. Sound scattering by cylinders of finite length. III Deformed cylinders. J. Acoust. Soc. Am. 86, 691-705.

Stanton, T.K., 1989. Simple approximate formulas for backscattering of sound by spherical and elongated bodies. J. Acoust. Soc. Am. 86, $1499-1510$.

Stanton, T.K., 1990. Sound scattering by spherical and elongated shelled bodies. J. Acoust. Soc. Am. 88, 1619-1633.
Stanton, T.K., Chu, D., Wiebe, P.H., Clay, C.S., 1993. Average echoes from randomly oriented random-length finite cylinders: zooplankton models. J. Acoust. Soc. Am. 94, 3463-3472.

Stanton, T.K., Wiebe, P.H., Chu, D., Benfield, M.C., Scanlon, L., Martin, L., Eastwood, R., 1994. On acoustic estimates of zooplankton biomass. ICES J. Mar. Sci. 51, 505-512.

Wiebe, P.H., Madin, L.P., Haury, L.R., Harbison, G.R., Philbin, L.M., 1979. Diel vertical migration by Salpa aspera and its potential for large-scale particulate organic matter transport to the deep-sea. Mar. Biol. 53, 249-255.

Wiebe, P.H., Greene, C.H., Stanton, T.K., Burczynski, J., 1990. Sound scattering by live zooplankton and microneckton: Empirical studies with a dual-beam acoustical system. J. Acoust. Soc. Am. 88, 2346-2360. 